Preprint-Version of the article published as Heinrichs et al. (2017). Introduction of car sharing into existing car fleets in microscopic travel demand modelling. Personal and Ubiquitous Computing, ISSN 1617-4917, 1-11.

Official version can be downloaded at https://link.springer.com/article/10.1007/s00779-017-1031-3

\title{
Introduction of car sharing into existing car fleets in microscopic travel demand modelling
}

Matthias Heinrichs*, Daniel Krajzewicz, Rita Cyganski, Antje von Schmidt German Aerospace Center (DLR), Institute of Transport Research, Rutherfordstrasse 2, 12489 Berlin, Germany

* Corresponding author. Tel.: +49-30-67055-174; fax: +49-30-6705583.

E-mail address: matthias.heinrichs@dlr.de

\begin{abstract}
Microscopic travel demand models take the characteristics of every individual person of the modelled population into account for computing the travel demand for the modelled region. Car sharing is an old concept, but the combination of a car sharing fleet parked in public space with smartphone services to find available cars nearby offers a new mobility service. It enables people to use a fleet operator's cars by providing individual mobility on demand. However, integrating this mobility option into microscopic travel demand models still is a difficult task due to a lack of data. This paper shows an integrated approach to model car sharing as a new mode for transport within a travel demand model using disaggregated car fleets with car-specific attributes. The necessary parameters for mode choice are estimated from various surveys and integrated into an existing multi-nominal logit model. The proposed work is used to simulate the travel demand of a synthetic population for the German capital of Berlin. A comparison with the survey results shows that the proposed integration of car sharing meets the real-world data. Furthermore, it is shown that the mode choice reacts well for access restrictions for specific car segments and local accessibility influencing the trip lengths.
\end{abstract}

Keywords: car sharing; travel demand; microscopic modelling; car fleet; disaggregated cars; agent-based modelling 


\section{Motivation}

Classic 4-step transport models have been dominating the operational use for traffic simulation, measure assessment and decision-making for a long time. But flow-orientated modelling has certain limits, such as hardly achievable consistencies of trip chains or taking into account shared resources like cars in the same household. These challenges resulted in the use of microscopic demand models that address transport as the sum of trips of individuals [13]. Microscopic approaches maintain personal attributes such as driving licenses and manage shared household resources such as the available cars for computing consistent daily activity patterns, where cars are returned home at the end of a tour.

Car sharing (CS) is not a new concept. Station-based car sharing where cars are picked up and returned at a fixed location has been known for decades. In free-floating car sharing, the car fleet is entered and left parking in public space. The problem here used to be finding available cars nearby. Currently, smartphone and web technology have solved this issue, thus dramatically changing the usability of the car sharing concept enabling any subscriber to the service to use a car within a certain service area. As it is not necessary to return the car, it may be used for one-way trips, which allows a very flexible usage of the car.

In this paper, we focus on free-floating car sharing and its inclusion in microscopic travel demand models. Usually, the mode choice is implemented by a discrete choice model in microscopic travel demand models. The most common approach is a multinomial logit (MNL) model, which is usually estimated from survey data. Unfortunately, no sufficient data set for obtaining the car sharing MNL parameters by regression is known to the authors, yet. This work presents an approach where these missing factors are estimated after the MNL parameters of other transport modes have been calculated. The CS parameters are fitted to available empirical findings from different surveys. To evaluate the quality of the proposed mode choice model, the resulting mode share is compared to actual survey data. This leads to a mode choice model which successfully integrates car sharing into a microscopic travel demand model using a disaggregated car fleet.

The remainder is structured as follows. First, the travel demand model used for the research is described in section 2 including a detailed description of the used mode choice. Section 3 describes how car sharing is integrated in the proposed model and which empirical base is used. In section 4, the used simulation scenarios are explained. The results are given in section 5. This document ends with a summary, given in section 6 .

\section{Proposed model}

This section presents the microscopic activity-based travel demand model called Travel Activity PAttern Simulation (TAPAS) [8,9]. Figure 1 shows the general mode of operation of the simulation model which consists of four parts: population generation, activity generation, location choice and mode choice. The result of a TAPAS simulation mainly consists of a day plan for each person contained in the simulated population. This day plan consists of activities, locations, used modes and travel times. The final plan of each simulated person is checked for feasibility with respect to time and budget constraints. If the plan gets rejected, plan generation is repeated until an acceptable plan is found.

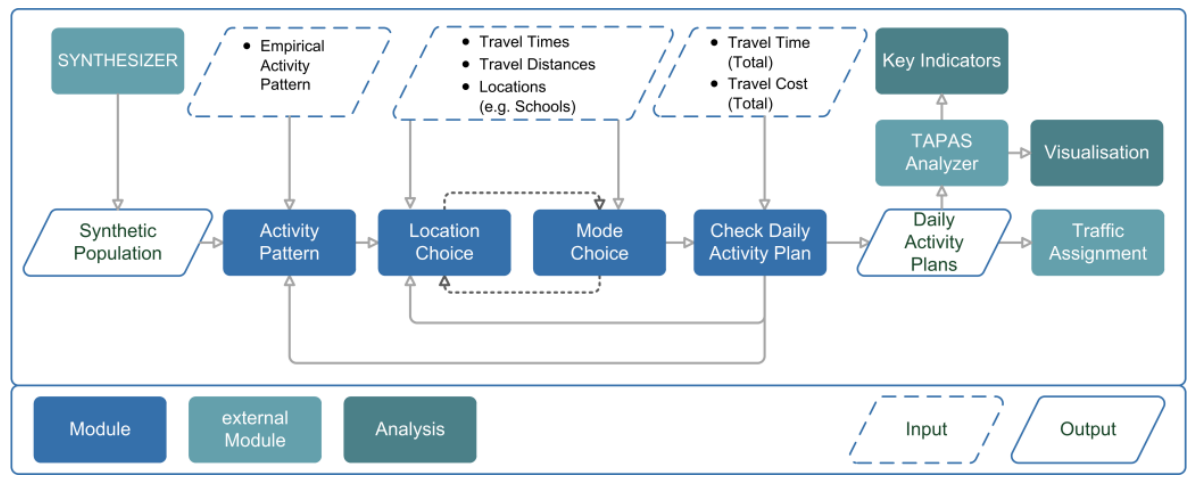

Figure 1: TAPAS Mode of Operation

The population in TAPAS is generated by combining various statistical data. In this case, the well-known Iterative Proportional Fitting (IPF) approach [3,7] was used to estimate joint distribution on household and person level for the 12 districts of Berlin. Afterwards, these distributions were used within the Iterative Proportional Updating (IPU) algorithm for calculating sample household weights. This weight-based procedure for stochastic drawing of 
households results in the generation of a synthetic population that closely matches the real-world distributions of socio-demographic attributes at household and person level [17]. Finally, the households are spatially distributed over the study area based on population density per block building. Each person within the synthetic population includes socio-demographic characteristics such as age, gender, employment status, mobility budget, public transport ticket, driving license and bike ownership. The associated households' attributes comprise the number of members, a specific total income and an available number of cars. The resulting population is stored in a database and can be used for simulating different scenarios.

The car ownership is modelled by assigning an externally specified fleet, which consists of the numbers of vehicles per size, value, and fuel type. Each household has an affinity to own up to two cars based on household size, income and number of driving licenses. The car affinity was derived from data of the SrV 2008 [1], one of the large national household travel studies (NHTS) in Germany. Shares are expressed by a probability vector for having zero, one or two cars.

TAPAS computes the daily activity plan for each person by finding locations for each activity and determining the mode to get there. The individual persons are processed at the household level. All persons from a synthetic household are processed individually but are limited by the household constraints like car availability and mobility budget. Consequently, a car can only be used by different persons if no overlap in time occurs. The activities are derived from reported diaries from the MiD 2008 [12]. The activities are subdivided into education, work, shopping, private matters, leisure and study. To increase the variance of possible day plans, persons and plans are grouped into several classes called person groups and activity scheme classes, respectively. Every person group has a probability vector for choosing one of the activity scheme classes. The probability to draw a specific plan from the scheme class is equally distributed [15].

After selecting the day plan for each individual, the plan is subdivided into tours. Each tour starts and ends at home, enabling the person to choose from the whole set of available modes every time she or he returns home. An example of a plan containing two tours is shown in Figure 2, where the first tour ends at 6 p.m. and the second tour starts at 7 p.m. The activities on each tour are processed in a hierarchical way (see Figure 2). Trips of high priority like work or education are processed first. Afterwards, activities of lesser priority are inserted into the trip chain by splitting existing trips from the previous step whereby limitations in choice of mode and location are taken into account. This is especially important for correctly modelling the usage of modes such as cars and bikes, where the transport vehicle has to be used during the entire trip and has to be returned to the home location.

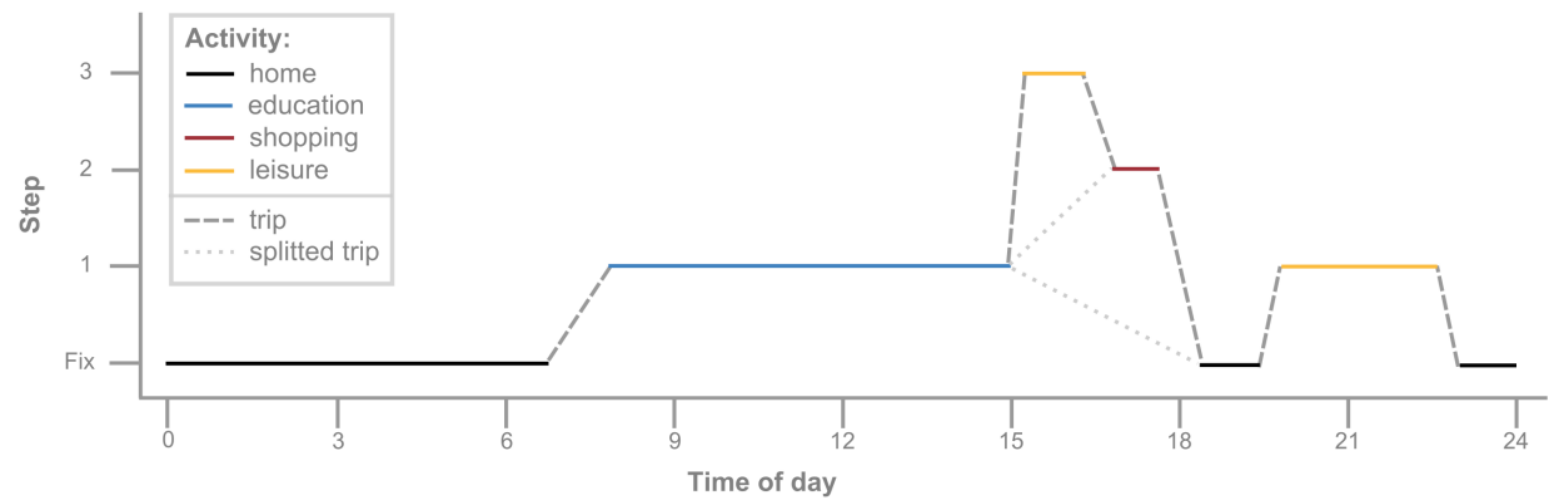

Figure 2: hierarchy of activities

For each activity, possible destinations are selected based on available transport modes, mode-specific accessibility, remaining capacity, previous and following destinations, time budget and an empirically determined search radius. The mode-specific accessibility takes vehicle restrictions into account. The access to restricted zones can be prohibited or penalized for certain modes or vehicle classes and hence those zones become less attractive for persons possessing restricted vehicles for location choice. Next, a specific mode is chosen, based on the availability of bikes and cars, a driving license, costs, travel times, local restrictions, a season ticket, age, trip purpose and the distance to the destination. All these factors are taken into account by a multinomial logit model described in sub-section 2.1. Finally, the total travel time and costs are compared to the original time and monthly mobility budget and unfeasible plans are rejected. In these cases, a new day plan is selected and the requirements are tested again.

The car fleet can be exchanged separately from the synthetic population. This makes delta analysis possible and specific effects of certain car fleet segments can be modelled. The cars have attributes for size, fuel type, costs per kilometer, maximum range, and restrictions that are specific to certain areas of the simulated region. Every car-owning household is equipped with unique instances of specific cars, enabling vehicle-specific cost calculation. 
The model has been calibrated by adjusting the search radius of the location choice for each type of activity and its respective location to achieve a valid modal split. As reference data for modal split, the survey SrV 2008 and MiD 2008 for Berlin were taken. The results are shown in Table 1. The validation shows very solid results with a slight overestimation of car passengers compared to the SrV. The MiD shows similar results, except that it reports a higher car and car passenger share than the $\mathrm{SrV}$ as well as TAPAS.

Table 1: Mode share comparison for 2008

\begin{tabular}{|l|l|l|l|l|l|}
\hline Mode & SrV 2008 & MiD 2008 & TAPAS & Deviation SrV & Deviation MiD \\
\hline Walk & 28.1 & 27.4 & 27.2 & -0.9 & -0.2 \\
\hline Bike & 12.5 & 12.2 & 12.7 & 0.2 & 0.5 \\
\hline Car & 25.1 & 28.1 & 25.6 & 0.5 & -2.5 \\
\hline Car passenger & 6.4 & 7.9 & 9.0 & 2.6 & 1.1 \\
\hline Public transport & 27.0 & 24.2 & 25.6 & -1.4 & 1.4 \\
\hline Others & 0.9 & 0.3 & 0.0 & -0.9 & -0.3 \\
\hline No. of trips & 329816 & 7859 & 1176367 & & \\
\hline
\end{tabular}

\subsection{Mode choice}

The multinomial logit model (MNL) for the mode choice calculates the utility for each mode. The probability of choosing mode $i$ is defined by

Equation 1: Multinomial Logit

$P_{i}=\frac{e^{\alpha_{i}+\beta_{i, 1} c_{1}+\ldots+\beta_{i, n} c_{n i}}}{\sum_{k} e^{\alpha_{k}+\beta_{k, 1} c_{1}+\ldots+\beta_{k, n} c_{n}}}$

The cost function is defined by a constant plus the sum of different factors $c$ and estimated weights $\beta$. The estimation of these parameters consists of two stages: First, identifying significant variables $c$ for the mode choice and second estimating the weights $\beta$ to fit the observed probability distribution $P$. These two stages are iterated to obtain a model which is sensitive to variations but also stable to insignificant deviations.

The selection of the significant variables strongly depends on the quality of the input data and the availability of input data in the modelled application. However, choosing too many variables reduces the variability of each one if the number of observations is insufficient. This could lead to overfitting the model. On the other hand, too few variables result in a model insensitive to changes. There are two kinds of factors: linear factors and binary ones. The linear factors depend on the current situation for the reported trip and are travel time, costs and age. The ordinal variable of available cars in the household can be treated as a linear factor, too. Furthermore, the number of interchanges on public transport (PT) rides was found significant, but only applies to PT trips. The interchanges are found to have exponential influence, thus the number of interchanges for PT trips results to a factor $c=e^{\text {interchanges }}$. The binary factors describe constant parameters, which can either be true or false in the current situation. If a certain condition is true, the according $\beta$ is taken into account, otherwise it is not. Significant factors are: driving license, season ticket for PT and trip purpose. The purpose is determined on a tour level, meaning if a work activity is part of the tour all trips have the attribute "work" enabled. This improves the quality of selecting a transport mode within trips that include different activities.

The travel time is split in a global factor applied to all modes and mode-specific modifiers to react to different perceptions of time in different modes. The travel time is composed of access, egress and actual travel time on the net. PT has two additional terms for the initial waiting time and interchange waiting time, to model different frequencies in the PT network.

The costs are modelled only for modes which have a measurable cost - for cars, this is the actual fuel costs per kilometer for each engine type. Since car passengers are modelled separately, they have to react to the costs as well. Otherwise, a rise in fuel prices would result in a modal shift from car drivers to car passengers until no one would drive a car by themselves anymore. PT costs are modelled according to the local pricing scheme or omitted if a season ticket was available for the reported trip.

The MNL is estimated using the software STATA12 on the reported mode choice for the trips of the SrV 2008. This survey contains 329816 valid trips including most of the necessary input parameters and the chosen mode as target variable. However, actual trip lengths and the car costs were missing in the input. Since the trips are reported 
georeferenced, the missing lengths were estimated by classic shortest path routing using the commercially available NavTeq digital car navigation network representation. The car costs were calculated on an average fuel-price of 10.6 eurocent $/ \mathrm{km}$.

The resulting factors including their significance can be found in Table 2. The log likelihood is -50758.671 while the $\log$ likelihood of the null-model is only -100998.896 . The likelihood ratio Chi-square test for the 64 used parameters is 100480.45 and the final Pseudo $\mathrm{R}^{2}$ by McFadden is 0.4974 .

Table 2: MNL factors

\begin{tabular}{|c|c|c|c|c|c|c|}
\hline & Walk & Bike & Car & Passenger & $\mathrm{PT}$ & Car sharing \\
\hline constant & 0 & $-6.06731^{* * *}$ & $-7.689375^{* * *}$ & $-10.0817^{* * *}$ & $-4.799272^{* * *}$ & $-6.3^{* * *}$ \\
\hline travel-time & \multicolumn{6}{|c|}{$-0.0025054^{* * *}$} \\
\hline mode specific $\mathrm{tt}$ & 0 & $0.0012123^{* * *}$ & $0.001641^{* * *}$ & $0.0015891^{* * *}$ & $0.0022148^{* * * *}$ & $0.001641^{* * * *}$ \\
\hline costs & 0 & 0 & $-0.5653694^{* * *}$ & $-0.4714332^{* * *}$ & $-0.7701009^{* * *}$ & $-0.5653694^{* * *}$ \\
\hline exp_interchange & 0 & 0 & 0 & 0 & $-0.0994185^{* * *}$ & 0 \\
\hline age & 0 & $0.0309613^{* * *}$ & $0.0481586^{* * *}$ & $0.038401^{* * *}$ & $-0.0592746^{* * *}$ & $-0.074118^{* * *}$ \\
\hline age*age & 0 & $-0.0005767^{* * *}$ & $-0.0005028^{* * *}$ & $-0.0002344^{* * *}$ & $0.0006074^{* * *}$ & $0.0006543^{* * *}$ \\
\hline driving license & 0 & $0.589425^{* * *}$ & 0 & $-0.5958377^{* * *}$ & $-0.1462389^{* * *}$ & 0 \\
\hline no of cars & $0.2416363^{* * *}$ & -0.0266353 & $0.8966269^{* * * *}$ & $1.276727^{* * *}$ & -0.0330338 & 0 \\
\hline season ticket & -0.1158329 & $-0.7413826^{* * *}$ & $-1.080744^{* * *}$ & $-0.4161085^{* * *}$ & 0 & 0 \\
\hline work & $-0.5804453^{* * *}$ & $0.3523357^{* * *}$ & $0.4038059^{* * *}$ & $-0.8959695^{* * *}$ & $0.5208496^{* * *}$ & $0.4038059^{* * *}$ \\
\hline education & $0.4541837^{* * * *}$ & $0.9879072^{* * *}$ & $1.294749^{* * *}$ & 0.0061965 & $0.8593692^{* * *}$ & $1.294749^{* * *}$ \\
\hline shopping & $0.189331^{\text {** }}$ & $0.1837389^{* *}$ & $0.5481002^{* * *}$ & $0.7332294^{* * *}$ & 0.0426857 & $0.5481002^{* * *}$ \\
\hline errant & $-0.7375521^{* * *}$ & $-0.6189397^{* * *}$ & -0.1084135 & -0.1287232 & -0.0174906 & -0.1084135 \\
\hline leisure & $-0.4986821^{* * *}$ & $-0.4598747^{* * *}$ & $-0.2716768^{* * *}$ & -0.1108767 & $-0.6274424^{* * *}$ & $-0.2716768^{* * * *}$ \\
\hline
\end{tabular}

\section{Integration of car sharing}

Car sharing (CS) combined with web and smartphone technology offers a service of picking up a rental car without any rental agent. There are two varieties of this service: station-based CS where cars are picked up and returned, and a free-floating service where users can pick up a car wherever they find one and leave it at their destination within a specified service area.

The price of the rental is charged per kilometer or minute and generally covers fuel costs and insurance. The observed prices are much higher than the average fuel costs of a private car but low compared to taxi fares. However, to use this mode one has to be registered with the service and must have possessed a driving license for a certain period, e.g. two years. Unfortunately, information and data published by service providers is insufficient for estimating a proper model for computing the probability of being a registered CS service user. Furthermore, many users tend to register with multiple services since the registration fee is very low, if there is any at all. Therefore, estimating proper membership figures is difficult. In the survey SrV 2013 [2], a first glance of CS usage is presented. All persons were asked if they are registered at least with one CS service and CS was an option for mode choice. In $2013,8.3 \%$ of the people that would be legally allowed to use CS where registered (see Table 3)

Table 3: Registered CS users in Berlin 2013 (Filter: Age>20 with driving license)

\begin{tabular}{|l|l|l|}
\hline Registered to CS & 906 & $8.3 \%$ \\
\hline Unregistered & 10017 & $91.7 \%$ \\
\hline
\end{tabular}

However, only 49 out of 50284 trips were realized using CS, resulting in a very low mode share of $0.1 \%$ (see Table 4). In 2013, CS was still emerging in the system, therefore we weighted the reported trips in a way that resembles a situation where the registration rate of every person above the age of 20 with a driving license is $100 \%$. The results are shown in Table 4. 
Table 4: Mode Share in Berlin SrV 2013 and extrapolated for car sharing

\begin{tabular}{l|r|r} 
& \multicolumn{1}{|c|}{ SrV 2013} & $\begin{array}{l}\text { SrV 2013 CS } \\
\text { extrapolated }\end{array}$ \\
\hline Walk & $30.96 \%$ & $30.64 \%$ \\
Bike & $12.52 \%$ & $12.39 \%$ \\
Car & $22.50 \%$ & $22.26 \%$ \\
Passenger & $7.04 \%$ & $7.22 \%$ \\
PT & $25.86 \%$ & $25.59 \%$ \\
Car sharing & $0.07 \%$ & $0.87 \%$ \\
Other & $1.05 \%$ & $1.04 \%$
\end{tabular}

Unfortunately, the SrV 2013 was provided on a much coarser level of georeference (23 regions) than the predecessor SrV 2008 (195 regions), which made it impossible to calculate a fine resolution for travel time and costs based on distance. Therefore, the MNL was not estimated using the new data, but the older one from 2008.

Another issue is the structure of CS usage. A short survey conducted in partnership with CS providers [5] in 2013 and 2015 amongst persons who used a CS service at least once in the past year gave an insight into the age structure of CS users. The results are shown in Figure 3. The first survey was done via a questionnaire in the car. The second survey was performed via a website, it was sent to all registered users by e-mail. Due to the different polling procedures, the total number of answers differs a lot: the number of responses dropped from 850 in 2013 to 328 in 2015. The small number of observations explains the oscillating shape of the plot for 2015 in Figure 3. Despite this polling artefact, it becomes clear that in 2013 and 2015, it was mainly male persons and persons below the age of 45 who used CS. However, the gap between those groups of persons and the rest became smaller from 2013 to 2015.

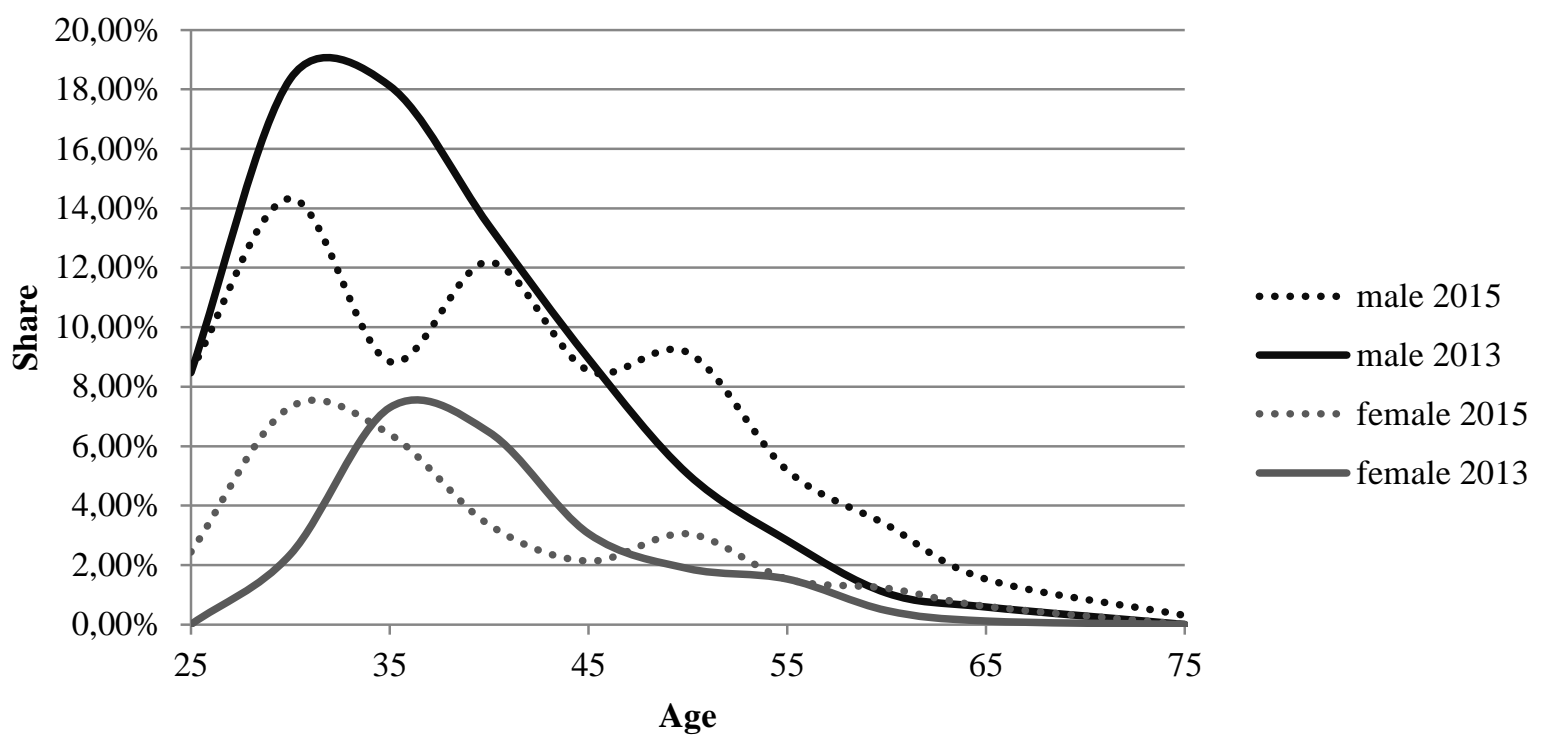

Figure 3: Usage of car sharing in Berlin, $\mathbf{n}(2013)=850, \mathbf{n}(2015)=328$

Due to the small number of reported CS trips, a full integration into the MNL was not possible. Therefore, we introduced CS with the same parameters as a car without variables that describe stated preferences like number of cars in the household and season ticket. The utility of the age for car trips did not reflect the usage of CS (see black line in Figure 4). We calculated the linear and quadratic age factors of the MNL cost function by standard three-point polynomial fitting. The three reference points were the respectively reported usage amounts of all persons aged 35, 45 and 55 derived from Figure 3 for the year 2013. The result of this manual process can be seen in Figure 4. One sees the polynomial fitting creates a minimum at the age of 56.639 while this is not the case in Figure 3 . This is not plausible and we had to fix this modelling flaw by limiting the maximum age to 57 in the simulation for the CS cost function. This fix is shown by the grey dotted line in Figure 4. 


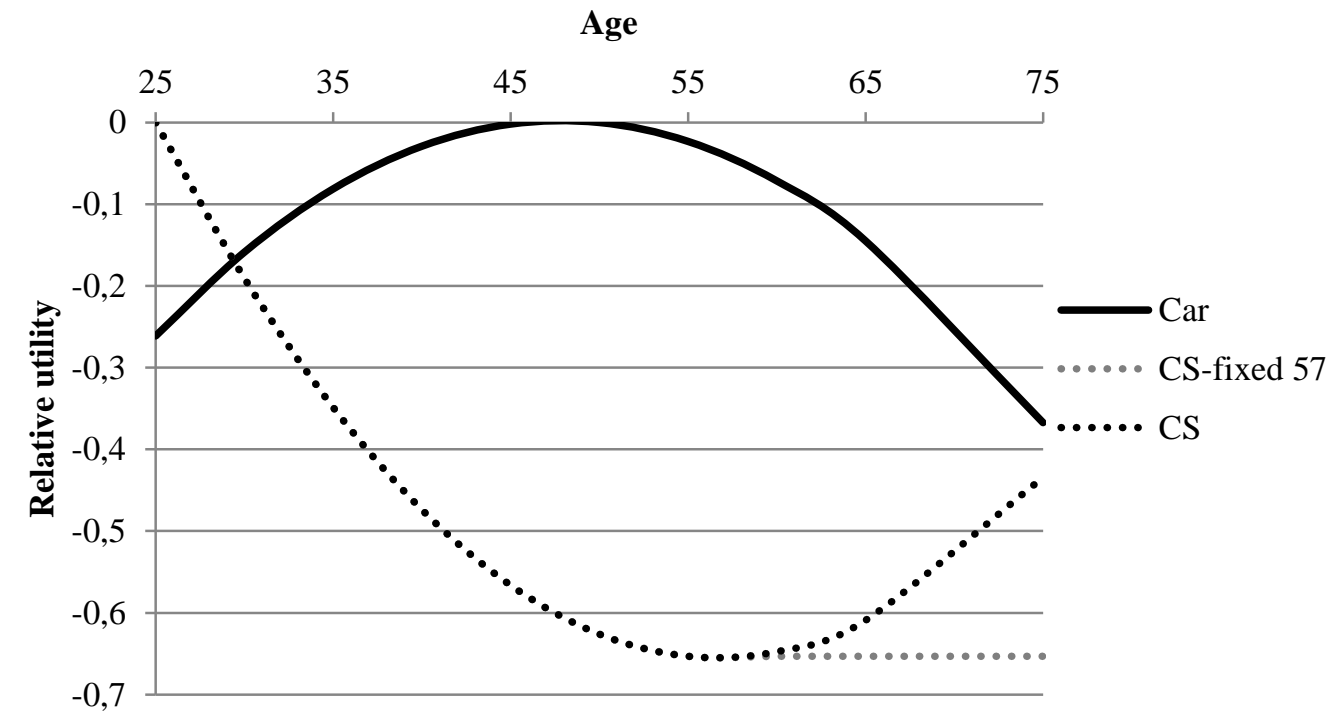

Figure 4: Relative influence of the age on car usage and car sharing in the MNL

The mode-specific constant was chosen to fit the extrapolated mode share of CS shown in Table 4. Currently there is no valid model for CS membership available to the authors. Therefore, we assumed everyone is registered to such a service. The final MNL parameters for CS are shown in Table 2.

\section{Defining the simulated area and example measures}

The model has been used to simulate the travel behavior of an average weekday for all modes of transport within a regional analysis area $[10,11]$. In this example, the simulation covers the area of the city of Berlin, Germany, with 3.3 million inhabitants. The population, the car fleet and the fuel prices have been parametrized to meet the values of the reference year 2010 of the official traffic forecast "Verkehrsprognose 2030" (VP2030) [16]. The population distribution is sampled from the official German micro-census data [14] and consists of 3.3 million persons living in 1.9 million households. The sample was fitted to meet the distribution of age, gender, status, household size and income. The availability of driving licenses and season tickets is modelled based on gender, status and age using data from the SrV 2008. The distribution of age, household size, income and driving licenses of the resulting synthetic population are shown in Figure 5. 

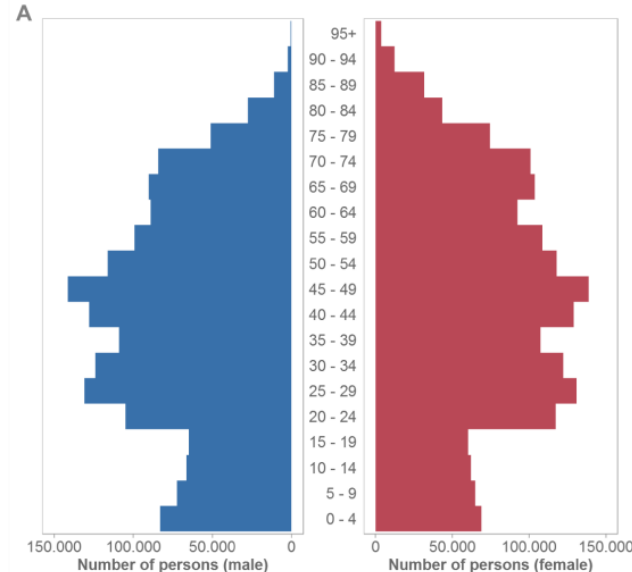

C

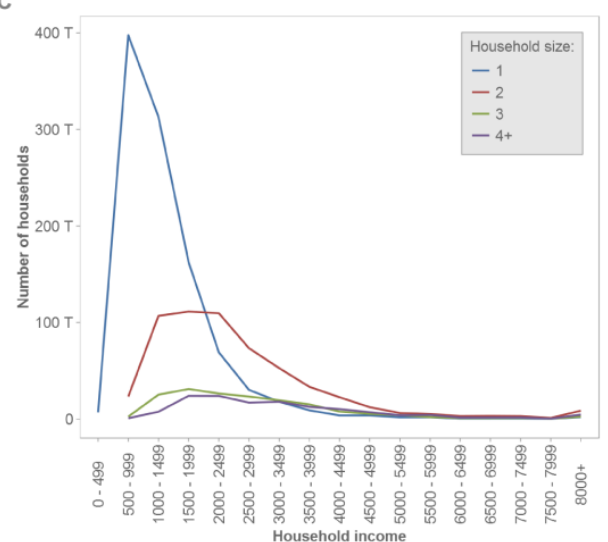

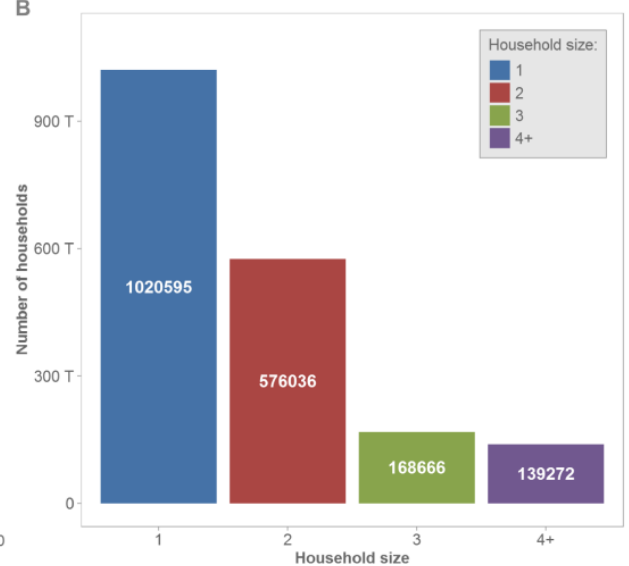

D

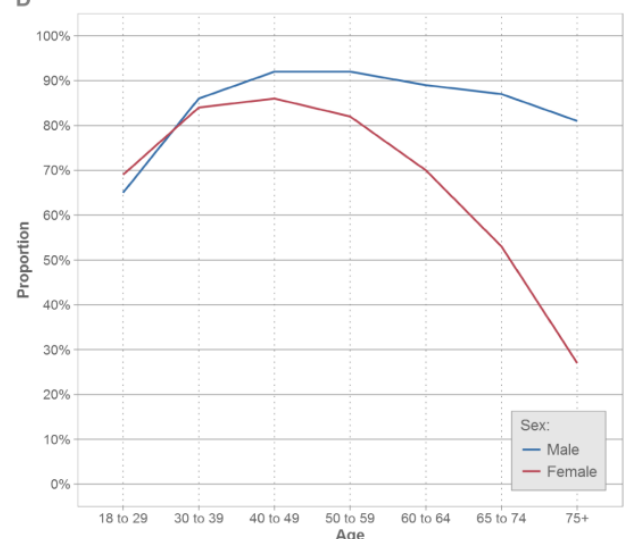

Figure 5: (a) age pyramid; (b) household size; (c) income; (d) driving license of the synthetic population of Berlin 2010

The car fleet is distributed based on income, household size and driving license availability with a maximum of two cars per household, reflecting the share of less than $1 \%$ of households possessing more than 2 cars in Berlin. After all, $41 \%$ of the synthetic households have no car, $49 \%$ have one car and $10 \%$ have two cars. Please note that the population density is not integrated in the distribution algorithm because of insufficient spatial resolution of the data. This leads to a slightly overestimated motorization rate in the inner city. The motorization rate and cars per $\mathrm{km}^{2} \mathrm{can}$ be seen in Figure 6.

The car fleet is segregated into three engine classes: gasoline, diesel and a combination of compressed natural gas (CNG) and liquefied petroleum gas (LPG) vehicles. The market share of other engine types was only marginal in Germany in 2010 and is therefore not accounted for. The average costs are shown in Table 5 and are calculated based on fuel prices, consumption, taxes and distribution costs [4]. In 2010 the car sharing costs were 29ct/minute. To keep the price comparable, the average car speed in the study area of $28.3 \mathrm{~km} / \mathrm{h}$ reported by the $\mathrm{SrV} 2008$ is taken into account, resulting in a price per kilometer of $58 \mathrm{ct}$. 

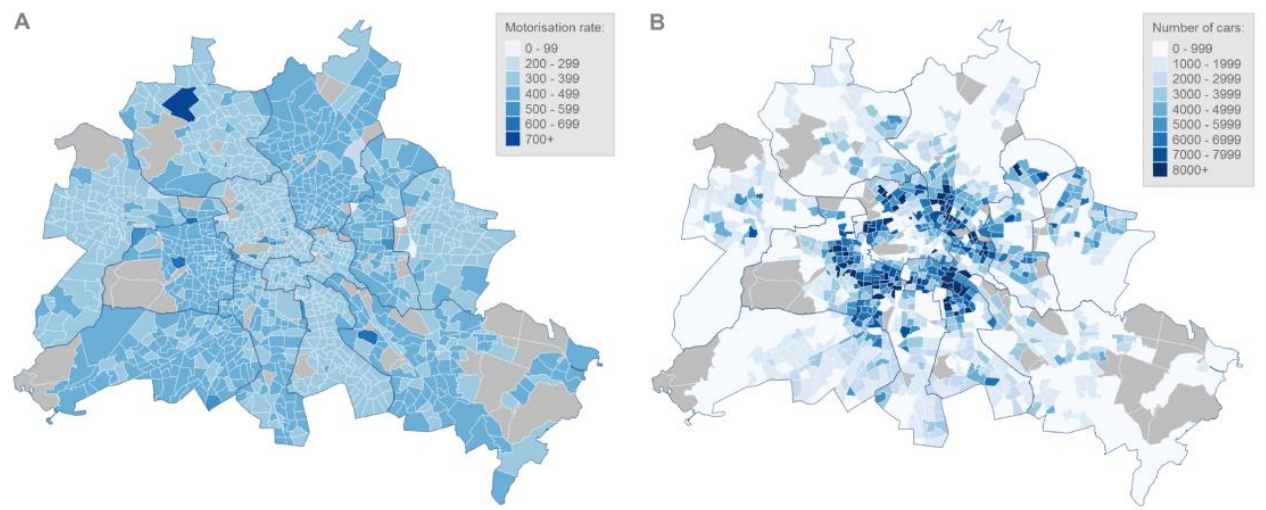

Figure 6: (a) cars per 1000 persons; (b) number of cars per $\mathbf{k m}^{2}$

Table 5: Kilometer costs by fleet segment

\begin{tabular}{|l|l|l|l|}
\hline Gasoline & Diesel & Gas & Car Sharing \\
\hline $11.6 \mathrm{ct} / \mathrm{km}$ & $8.9 \mathrm{ct} / \mathrm{km}$ & $5.5 \mathrm{ct} / \mathrm{km}$ & $58 \mathrm{ct} / \mathrm{km}$ \\
\hline
\end{tabular}

The distribution of engine types is based on the official registration statistics for 2010 [6]. The total number of cars is taken from the SrV 2008 and not from the official registration office, because the SrV 2013 reports that $20 \%$ of the cars owned by the population of Berlin are registered elsewhere and therefore the official numbers of registered vehicles do not represent the real number of cars used in Berlin. The numbers are shown in Table 6.

Table 6: Number of cars and fuel type distribution

\begin{tabular}{|l|l|l|l|}
\hline Total & Gasoline & Diesel & CNG/LPG \\
\hline 1300333 & $962246(74.0 \%)$ & $323913(24.9 \%)$ & $14174(1.1 \%)$ \\
\hline
\end{tabular}

Four scenarios are simulated for examining the effects of different car fleets:

1. The reference scenario for 2010

2. Enabled car sharing

3. An access restriction to the city center for diesel cars (see Figure 7), no car sharing

4. $\quad$ Same as 3 but with car sharing

The last two scenarios show the effects of using disaggregated vehicle fleets in conjunction with access restrictions and car sharing. Due to regulations to limit fine particulate matter, highly polluting cars have been banned in the inner city area since 2008. This could happen again for regulating $\mathrm{NO}_{\mathrm{x}}$ emissions for diesel engines and the scenarios three and four replicate variants of such a measure. Such a measure could also have a significant impact on the ownership of diesel cars in the city center. However, replacement of the car fleet is no subject of this work, so the car fleet remains unchanged. Again, scenario three lacks a car sharing offer while in the fourth scenario car sharing is enabled again to see if this mode choice compensates the restricted accessibility. However, this assumes that the CS fleet consists of unrestricted cars.

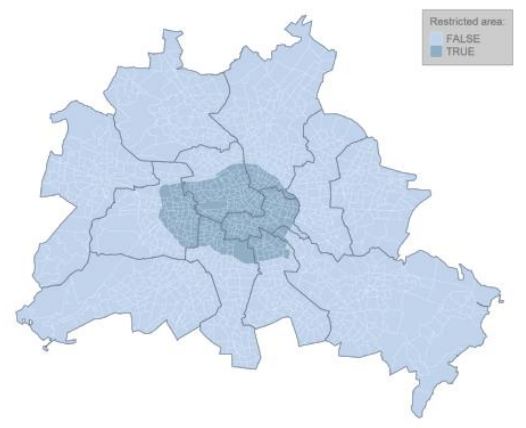

Figure 7: restricted area in Berlin 


\section{Results}

In this section, the results from the simulation of the travel demand using the four scenarios are shown and discussed. First, we briefly discuss the overall model results. Second, the plausibility of the car sharing model compared to first survey data is discussed. Third, a car-specific analysis of the results is given, pointing out how car sharing affects individual car fleet segments in certain scenario cases.

The overall scenario results for modal split, trip lengths per mode and activity type are shown in Table 7.

Table 7: Number of trips, modal split and trip lengths of different scenarios

\begin{tabular}{|l|l|l|r|r|r|l|r|r|}
\hline & \multicolumn{2}{|c|}{ Scenario 1 } & \multicolumn{2}{c|}{ Scenario 2 } & \multicolumn{2}{c|}{ Scenario 3 } & \multicolumn{2}{l|}{ Scenario 4 } \\
\hline Mode & Modal Split & $\begin{array}{l}\text { Avg. } \\
\text { length }\end{array}$ & Modal Split & $\begin{array}{l}\text { Avg. } \\
\text { length }\end{array}$ & $\begin{array}{l}\text { Modal } \\
\text { Split }\end{array}$ & $\begin{array}{l}\text { Avg. } \\
\text { length }\end{array}$ & $\begin{array}{l}\text { Modal } \\
\text { Split }\end{array}$ & $\begin{array}{l}\text { Avg. } \\
\text { length }\end{array}$ \\
\hline Walk & $27.24 \%$ & 1373.18 & $27.38 \%$ & 1375.08 & $27.63 \%$ & 1376.78 & $27.68 \%$ & 1367.67 \\
\hline Bike & $12.65 \%$ & 5119.58 & $12.47 \%$ & 5135.52 & $13.15 \%$ & 5159.23 & $12.84 \%$ & 5170.02 \\
\hline Car & $25.50 \%$ & 7045.29 & $25.00 \%$ & 7111.84 & $23.38 \%$ & 7025.01 & $23.16 \%$ & 7072.93 \\
\hline Car pas. & $8.97 \%$ & 7780.22 & $8.91 \%$ & 7839.40 & $9.54 \%$ & 7790.76 & $9.44 \%$ & 7820.18 \\
\hline PT & $25.64 \%$ & 7808.28 & $25.41 \%$ & 7833.01 & $26.30 \%$ & 7820.56 & $26.00 \%$ & 7845.02 \\
\hline CS & $0.00 \%$ & 0.00 & $0.83 \%$ & 5048.17 & $0.00 \%$ & 0.00 & $0.88 \%$ & 5078.20 \\
\hline
\end{tabular}

Comparing the modal splits of scenario 2 in Table 7 with the modal splits of Table 4 shows that the modelled usage of CS meets quite well the extrapolated share of the SrV 2013. However, there was a noticeable shift from car and passenger trips to walk trips from SrV 2008 to SrV 2013, which was mainly caused by changed car ownership between these years. In scenario 3 the restricted area was activated. A strong shift from car trips to trips performed by bike and PT can be seen, while walking seems not to be an alternative due to the limited range. The last scenario shows the results for enabling car sharing in the city center. Only marginal changes, if any, could be observed. Additionally, we analyzed the trips by car in more detail by calculating the fleet shares of all trips for each scenario. The trips where separated in destinations within the restricted city center and destinations outside it. The results are shown in Table 8. In scenario 1 one sees that diesel and LPG/CNG cars are more frequently used compared to gasoline cars due to their lower prices. The fleet share is the same over the whole city area. The spatial distribution of the car trips can be seen in Figure 8. One sees the higher concentration in the city center but also the polycentric character of the study area with highly frequented destinations in the west, southeast, southwest and northwest.

Table 8: Fleet share of car trips

\begin{tabular}{|l|r|r|r|r|}
\hline & Gasoline & \multicolumn{1}{|c|}{ Diesel } & \multicolumn{1}{l|}{ LPG/CNG } & Car sharing \\
\hline Total fleet share & $74.00 \%$ & $24.91 \%$ & $1.09 \%$ & - \\
\hline Scen .1 & $67.34 \%$ & $31.10 \%$ & $1.56 \%$ & $0.00 \%$ \\
\hline Scen. 1 - inner & $67.20 \%$ & $31.24 \%$ & $1.56 \%$ & $0.00 \%$ \\
\hline Scen. 1 - outer & $67.40 \%$ & $31.05 \%$ & $1.55 \%$ & $0.00 \%$ \\
\hline Scen. 2 & $65.20 \%$ & $30.02 \%$ & $1.56 \%$ & $3.23 \%$ \\
\hline Scen. 2 - inner & $64.25 \%$ & $29.84 \%$ & $1.57 \%$ & $4.34 \%$ \\
\hline Scen. 2 - outer & $65.64 \%$ & $30.10 \%$ & $1.55 \%$ & $2.71 \%$ \\
\hline Scen. 3 & $84.46 \%$ & $13.90 \%$ & $1.64 \%$ & $0.00 \%$ \\
\hline Scen. 3 - inner & $98.10 \%$ & $0.00 \%$ & $1.90 \%$ & $0.00 \%$ \\
\hline Scen. 3 - outer & $79.33 \%$ & $19.13 \%$ & $1.55 \%$ & $0.00 \%$ \\
\hline Scen. 4 - & $81.24 \%$ & $13.48 \%$ & $1.61 \%$ & $3.67 \%$ \\
\hline Scen. 4 - inner & $92.31 \%$ & $0.00 \%$ & $1.90 \%$ & $5.80 \%$ \\
\hline Scen. 4 - outer & $76.92 \%$ & $18.74 \%$ & $1.49 \%$ & $2.84 \%$ \\
\hline
\end{tabular}

The higher fleet share of CS within the city center in scenario 2 is mainly caused by the lower distances travelled to reach a destination. For longer trips outside the center CS is less attractive due to its high costs. The spatial distribution of CS trips is shown in Figure 9. The trips concentrate in the core of the city center and fade out towards the outskirts, due to the longer distances between locations. Scenario 3 shows the expected effect that no diesel car enters the inner city. However, due to the restricted access a lot of trips outside the center are replaced by gasoline and LPG/CNG cars, especially if a household owns more than one car and has the option to choose. The spatial distribution of the change in trips is shown in Figure 8. There is a general decline across the whole city center except in some peripheral areas. In scenario 4, the share of CS trips is slightly higher than in scenario 2. But the growth comes mainly from a higher share of CS trips in the city center, where CS has become a true alternative for people owning diesel cars. In Figure 9, the change of CS trips between scenario 2 and 4 is shown. The change is not uniform 
but in general an increase of trips in the center can be seen. Comparing the differences between Figure 8 and Figure 9 it becomes clear that CS behaves different than car trips because of to an increased usage in the city center. Hence, CS is an alternative for critical trips to the city center in cases where biking or PT could not provide an acceptable alternative.

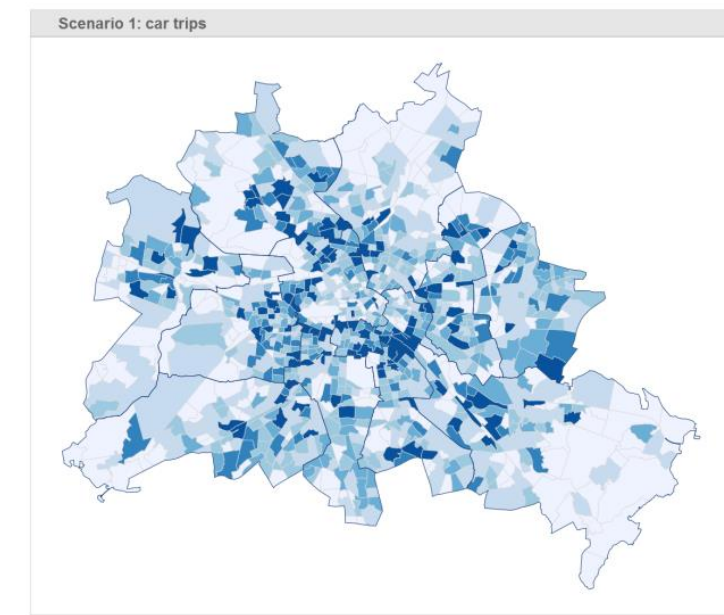

Number of trips: $\quad 0-99 \quad 100-199 \square 200-299 \square 300-399 \square-400-499 \square 500+$

Figure 8: Distribution of car trip destinations

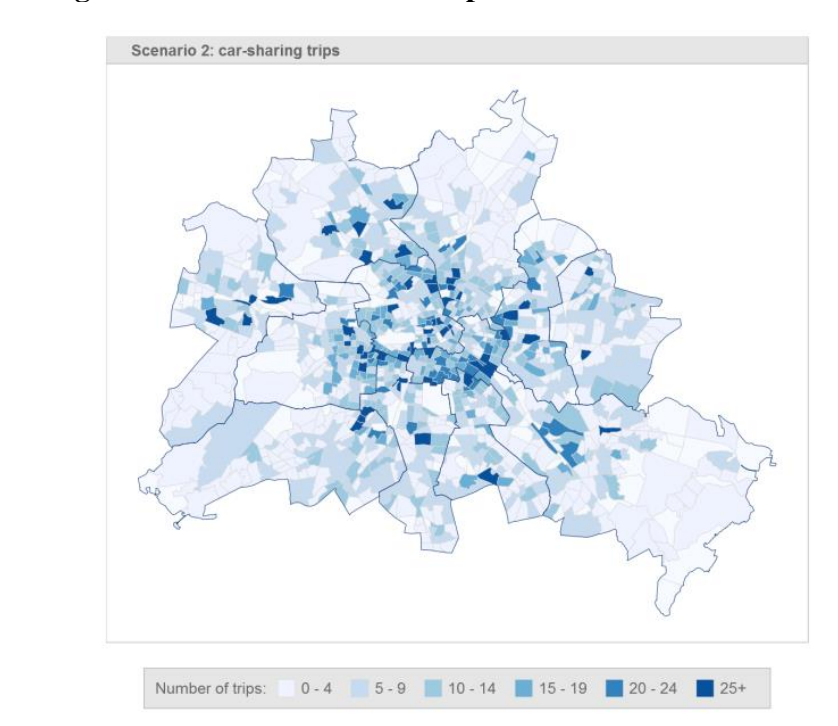

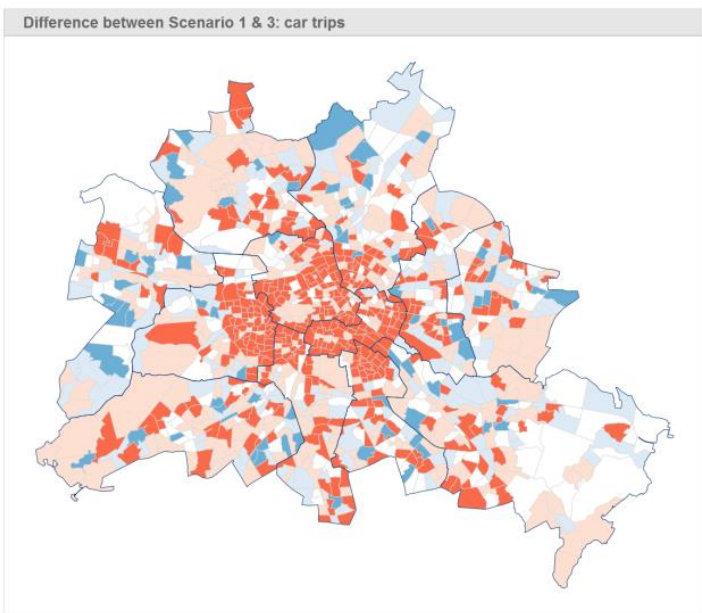

Number of trips (Difference): $\mathbf{E}-25[+] \quad-25$ to $-5 \quad-5$ to $5 \quad 5$ to $25 \quad\left[\begin{array}{ll}25 & {[+]}\end{array}\right.$

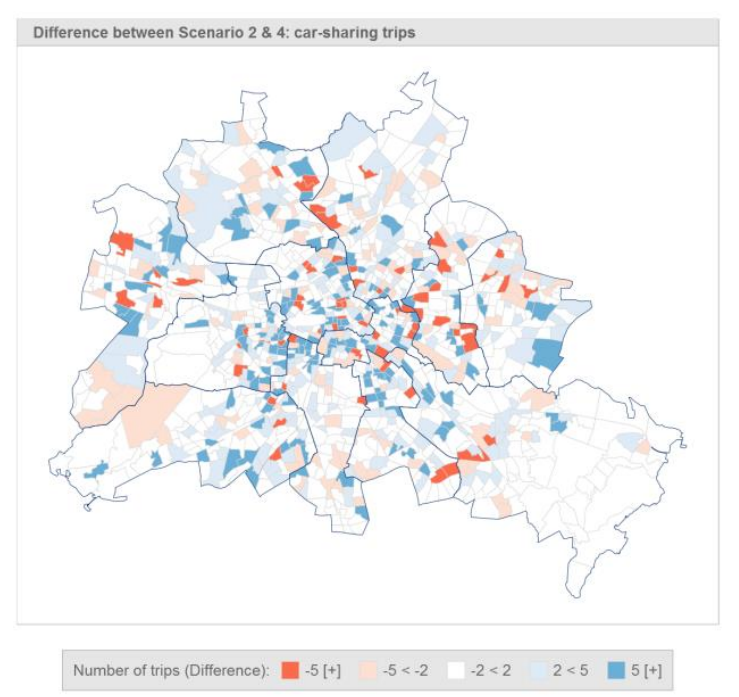

Figure 9: Distribution of car sharing destinations

Table 9: Modal Split for households owning different car types

\begin{tabular}{|l|rr|rr|rr|rr|}
\hline & \multicolumn{2}{|c|}{ Scenario 1 } & \multicolumn{2}{c|}{ Scenario 2 } & \multicolumn{2}{c|}{ Scenario 3 } & \multicolumn{2}{c|}{ Scenario 4 } \\
\hline & Gasoline & Diesel & Gasoline & Diesel & Gasoline & Diesel & Gasoline & Diesel \\
\hline Walk & $23.66 \%$ & $23.14 \%$ & $23.91 \%$ & $23.38 \%$ & $23.97 \%$ & $24.48 \%$ & $24.09 \%$ & $24.68 \%$ \\
\hline Bike & $10.50 \%$ & $9.85 \%$ & $10.37 \%$ & $9.70 \%$ & $10.54 \%$ & $12.49 \%$ & $10.35 \%$ & $12.27 \%$ \\
\hline Car & $37.71 \%$ & $39.98 \%$ & $37.06 \%$ & $39.60 \%$ & $37.35 \%$ & $30.19 \%$ & $36.86 \%$ & $29.98 \%$ \\
\hline Passenger & $10.35 \%$ & $10.18 \%$ & $10.30 \%$ & $10.32 \%$ & $10.38 \%$ & $13.03 \%$ & $10.31 \%$ & $13.06 \%$ \\
\hline PT & $17.77 \%$ & $16.85 \%$ & $17.64 \%$ & $17.00 \%$ & $17.77 \%$ & $19.81 \%$ & $17.67 \%$ & $20.02 \%$ \\
\hline CS & $0.00 \%$ & $0.00 \%$ & $0.71 \%$ & $0.64 \%$ & $0.00 \%$ & $0.00 \%$ & $0.72 \%$ & $0.91 \%$ \\
\hline
\end{tabular}

Looking at the mode shares for households owning at least one gasoline or diesel car only, it is noticeable that diesel cars are used more often and on longer distances than gasoline ones (compare Table 9 Scenario 1 and 2). Comparing the $2^{\text {nd }}$ and $4^{\text {th }}$ scenario reveals that especially households with diesel cars displays an increase in CS trips, while the other households show no significant change in behavior between those two scenarios. 


\section{Conclusion}

The presented work shows a reasonable and - as far as available data can prove this - plausible integration of car sharing into a microscopic travel demand model and extends an existing MNL function by a new mode. The parameters for this function have been estimated using reasonable assumptions. We have shown that the proposed model behaves well and plausibly for various scenarios utilizing a disaggregated car fleet with car-specific measures. The integration into a disaggregated car fleet allows for the analysis of particular effects on different costs and access restrictions. Using a microscopic model produces findings for certain types of households and persons which would have been invisible in aggregate numbers.

This work provides a valid answer to the question of how car sharing is used in complex traffic systems at the present time and for the near future. But three questions remain unanswered until sufficient empirical knowledge is gained: Who uses car sharing? How does car sharing influence car ownership and the purchase of season tickets? How is the future of car sharing progressing? The proposed work aspires to answer these questions but further research should be done to improve the empirical background for the simulation model.

\section{References}

1. $\quad$ Ahrens G.-A. (2009) Endbericht zur Verkehrserhebung „Mobilität in Städten - SrV 2008“ und Auswertungen zum SrV-Städtepegel, Lehrstuhl für Verkehrs- und Infrastrukturplanung, TU Dresden. http://daten.clearingstelle-verkehr.de/224/1/Staedtepegel_SrV2008.pdf .

2. Ahrens G.-A. (2014) Tabellenbericht zum Forschungsprojekt „Mobilität in Städten - SrV 2013 Berlin“, http://www.stadtentwicklung.berlin.de/verkehr/politik_planung/zahlen_fakten/download/SrV_2013_Be rlin_Tabellen.pdf .

3. Beckman RJ, Baggerly KA, McKay MD. (1996) Creating Synthetic Baseline Populations. Transportation Research Part A: Policy and Practice, 30(6), pp. 415-429.

4. Bundesministerium für Umwelt Naturschutz Bau und Reaktorsicherheit (BMUB) (2014) Renewbility, http://www.renewbility.de/. Accessed 1 May 2017

5. Bundesministerium für Umwelt Naturschutz Bau und Reaktorsicherheit (BMUB) (2015) WiMobil, http://www.erneuerbar-mobil.de/de/projekte/foerderung-von-vorhaben-im-bereich-derelektromobilitaet-ab-2012/ermittlung-der-umwelt-und-klimafaktoren-der-elektromobilitaet/wimobil

6. Kraftfahrzeugbundesamt (2011) Bestand an Kraftfahrzeugen und Kraftfahrzeuganhängern nach Zulassungsbezirken, 1. Januar 2011, http://www.kba.de/SharedDocs/Publikationen/DE/Statistik/Fahrzeuge/FZ/2011/fz1_2011_pdf.pdf?_bl $\mathrm{ob}=$ publicationFile $\& \mathrm{v}=6$. Accessed 1 May 2017

7. Deming WE, Stephan FF (1940) On a Least Squares Adjustment of a Sampled Frequency Table When the Expected Marginal Totals Are Known. Annals of Mathematical Statistics, 11, pp. 427-444.

8. Heinrichs M, Krajzewicz D, Cyganski R, von Schmidt A, (2016) Disaggregated car fleets in microscopic travel demand modelling, The 7th International Conference on Ambient Systems, Networks and Technologies (ANT 2016), Procedia Computer Science 83, pp. 155 - 162

9. Hertkorn G (2005) Mikroskopische Modellierung von zeitabhängiger Verkehrsnachfrage und von Verkehrsflußmustern. Dissertation German Aerospace Centre, Institute of Transport Research.

10. Höltl A, Heinrichs M, Macharis C (2014) Analysis of rebound effects resulting from improved vehicle efficiency applied to the Berlin city network. Sustainable Urban Transport Transport and Sustainability, 7, pp. 229-249. ISBN 978-1-78441-616-4.

11. Justen A, Cyganski R. (2008) Decision-making by microscopic demand modeling: a case study. Transportation decision making: issues, tools and case studies, Venice. ISBN 9-78-88-96049-06-8.

12. Lenz B, Nobis C, Köhler K, Mehlin M, Follmer R, Gruschwitz D, Jesske B, Quandt S. (2010) Mobilität in Deutschland 2008. DLR Project Report, http://daten.clearingstelle-verkehr.de/223/ http://elib.dlr.de/68010/. Accessed 1 May 2017

13. McNally MG, Rindt C. (2012) The activity-based approach. Handbook of Transport Modelling, In: Henscher DA, Button KJ, editors, Elsevier, pp. 53-69.

14. Statistisches Bundesamt (2010) Der Mikrozensus stellt sich vor. https://www.destatis.de/DE/ZahlenFakten/GesellschaftStaat/Bevoelkerung/Mikrozensus.html. Accessed 1 May 2017

15. Varschen C, Wagner P. (2006) Mikroskopische Modellierung der Personenverkehrsnachfrage auf Basis von Zeitverwendungstagebüchern. Integrierte Mikro-Simulation von Raum- und Verkehrsentwicklung. Theorie, Konzepte, Modelle, Praxis, AMUS, pp 63-69. 
16. Verkehrsprognose 2030, https://www.bmvi.de/SharedDocs/DE/Artikel/G/verkehrsprognose-2030.html and http://daten.clearingstelle-verkehr.de/276/. Accessed 1 May 2017

17. Ye X, Konduri K, Pendyala RM, Sana B, Waddell P (2009). A methodology to match distributions of both household and person attributes in the generation of synthetic populations. Presented at 88 th Annual Meeting of the Transportation Research Board, 1 Washington, D.C. 